\title{
Long-Term Safety of a Novel Angiotensin Receptor Blocker, Fimasartan, According to the Absence or Presence of Underlying Liver Disease in Korean Hypertensive Patients: A Prospective, 12-Month, Observational Study
}

This article was published in the following Dove Press journal: Drug Design, Development and Therapy

\author{
Gyu Chul Oh (D) \\ Kwon Wook Joo iD ${ }^{2}$ \\ Myung-A Kim ${ }^{3}$ \\ Dong-Ju Choi iD ${ }^{4}$ \\ Yoon Jun Kim iD ${ }^{5}$ \\ Hae-Young Lee (iD) \\ 'Division of Cardiology, Department of \\ Internal Medicine, Seoul National \\ University Hospital, Seoul, Korea; \\ ${ }^{2}$ Division of Nephrology, Department of \\ Internal Medicine, Seoul National \\ University Hospital, Seoul, Korea; \\ ${ }^{3}$ Division of Cardiology, Department of \\ Internal Medicine, Seoul Metropolitan \\ Government Boramae Hospital, Seoul, \\ Korea; ${ }^{4}$ Division of Cardiology, \\ Department of Internal Medicine, Seoul \\ National University Bundang Hospital, \\ Seongnam, Korea; ${ }^{5}$ Division of \\ Hepatology, Department of Internal \\ Medicine, Seoul National University \\ Hospital, Seoul, Korea
}

Purpose: Fimasartan, the ninth and most recent angiotensin receptor blocker (ARB) approved by the Korea Food and Drug Administration, has shown similar efficacy and safety profiles compared to other ARBs. However, due to being predominantly excreted by the hepatobiliary system, concerns on safety have been raised regarding its use in patients with underlying liver disease.

Patients and Methods: This prospective, 12-month, observational study evaluated patients with essential hypertension (HTN) receiving $\geq 1$ dose of fimasartan. Self-reported and physician-reported events were recorded and classified according to organ class and severity. Outcomes were compared according to the absence and presence of underlying liver disease. Results: A total of 601 patients were screened, and 566 patients who met predefined inclusion criteria were grouped according to the presence of underlying liver disease. Adverse events (AE) were reported in $28.7 \%$ (128/446) of patients without prior liver disease, while $42.5 \%$ (51/120) experienced events in the group with chronic liver disease. There was no difference in discontinuations due to liver function between patients with and without baseline liver disease $(1.1 \%$ [5] vs $2.5 \%$ [3], $\mathrm{p}=0.376$ ), and only a non-significant increase was observed in events associated to the hepatobiliary system in patients with chronic liver disease ( $9.7 \%$ [7] vs $2.7 \%$ [9], $\mathrm{p}=0.061)$. There were no deaths or serious adverse drug reactions (SADR) during the study period. In multivariate regression analysis, the presence of chronic liver disease (OR 2.01), female sex (OR 1.49) and old age (OR 1.12 for every 5-year increase) were independent predictors for the development of AE. Finally, no significant difference was observed in the reduction of systolic blood pressure after 12 months of treatment (least square mean change $-6.57 \pm 0.80 \mathrm{mmHg}$ for normal liver function group; $-7.65 \pm 1.59 \mathrm{mmHg}$ for chronic liver disease group; $\mathrm{p}=0.546$ ).

Conclusion: Long-term use of fimasartan for treatment of HTN was associated with a low rate of adverse events overall, especially in the absence of underlying liver disease. Even for patients with chronic liver disease, fimasartan treatment was well tolerated. Fimasartan could be a safe option for long-term treatment of essential HTN. ClinicalTrials.gov identifier: NCT02385721.

Keywords: fimasartan, safety, liver disease, essential hypertension, hepatobiliary excretion, adverse event

\section{Introduction}

Hypertension (HTN) is a widely prevalent disease that affects approximately $40 \%$ of the worldwide population. It is an established risk factor for cardiovascular
Correspondence: Hae-Young Lee; Yoon Jun Kim

I0I Daehak-ro, Jongno-gu, Seoul, Korea Tel +82 22072 0698; +82 22072308 I

Fax +82 236740805

Email hylee6I2@snu.ac.kr; yoonjun@snu.ac.kr 
disease and is responsible for $50 \%$ of 17 million annual cardiovascular deaths. ${ }^{1}$ HTN is also frequently prevalent together with other comorbidities such as diabetes mellitus, dyslipidemia and chronic kidney disease, which further increases cardiovascular risk. In recent years, updated guidelines have lowered the threshold of high blood pressure, with a goal to prevent adverse outcomes by early detection and intervention. ${ }^{2}$

Treatment of HTN is based on antihypertensive medications, achieved by using a combination of four classes of drugs: diuretics, beta-blockers, calcium-channel blockers and renin-angiotensin system (RAS) inhibitors. ${ }^{3}$ Among these drugs, RAS inhibitors seem to be the favorite, constituting around $50 \%$ of all medications used to treat HTN. ${ }^{4,5}$

Fimasartan (Boryung Pharmaceutical Co., Ltd., Kanarb ${ }^{\circledR}$, Seoul, Korea) is a non-protein angiotensin receptor blocker (ARB) that selectively blocks angiotensin type 1 receptors. ${ }^{6}$ It is the ninth and most recent ARB approved for use in HTN by the Korea Food and Drug Administration, and is also available for worldwide use. ${ }^{7}$ Fimasartan has been shown to have non-inferior, or even superior blood pressurelowering capabilities compared with losartan, ${ }^{8,9}$ and has also proven its safety in previous trials. ${ }^{10,11}$ Unlike other ARBs, fimasartan is predominantly excreted through the hepatobiliary system, with less than $3 \%$ of the administered dose detected in the urine. ${ }^{12}$ Due to this characteristic, fimasartan has not been recommended for use in patients with moderate to severe liver dysfunction. Furthermore, clinicians have also expressed concerns that long-term use of fimasartan may be associated with increased risk of liver injury, especially in patients with underlying liver disease. ${ }^{13}$ However, previous studies have only been performed for limited periods, and most studies excluded patients with chronic liver disease.

The current study aims to assess the long-term, hepatic safety of fimasartan use in real-world, hypertensive patients. Unlike other previous studies on fimasartan, patients with chronic liver disease were included and events were monitored for up to 1 year.

\section{Materials and Methods Study Design}

This study is a multi-center, prospective, observational study performed from May 2013 to December 2015. Patients diagnosed with essential HTN were screened in three medical centers in Korea (Seoul National University Hospital, Seoul, Korea; Seoul Metropolitan Government Boramae Hospital,
Seoul, Korea; Seoul National University Bundang Hospital, Seongnam, Korea). Patients receiving $\geq 1$ dose of fimasartan were enrolled in the study and followed-up for 12 months at 3-month intervals. Self-reported and physician-reported events were recorded and classified according to organ class and severity. The study was conducted in accordance with the declaration of Helsinki, and written informed consent was obtained before enrollment. Study protocols were approved by the institutional review board of each participating hospital (H-1303-050-472) and registered with ClinicalTrials.gov (NCT02385721).

Fimasartan was prescribed at a dose of 30 to $60 \mathrm{mg}$ once daily, with titration up to $120 \mathrm{mg}$ possible at the decision of the treating physician. Patients with creatinine clearance $<30 \mathrm{~mL} / \mathrm{min} / 1.73 \mathrm{~m} 2$ were initially prescribed $30 \mathrm{mg}$ once daily, with increases up to $60 \mathrm{mg}$ once daily. Patients were defined to have chronic liver disease if they had a history of liver cirrhosis or hepatocellular carcinoma (HCC), were carriers of chronic hepatitis $\mathrm{B}$ or $\mathrm{C}$ viruses. Incidence of adverse events (AE) was compared according to the presence and type of underlying liver disease (cirrhosis, HCC). The design of the study is described in Figure 1.

\section{Inclusion and Exclusion Criteria}

Patients aged $\geq 20$ years and who were newly prescribed with fimasartan within 1 month for the treatment of essential HTN were eligible for the study. Essential HTN was defined as systolic blood pressure (SBP) $\geq 140 \mathrm{mmHg}$ or diastolic blood pressure (DBP) $\geq 90 \mathrm{mmHg} .{ }^{14,15}$ Blood pressure was measured in the sitting position, after 5 mins of rest, using a semi-automated sphygmomanometer. The average value of multiple measurements was used. Subjects with a previous history of HTN, or those on anti-hypertensive medications were also defined as hypertensive. Patients were excluded from the study for the following reasons; hypersensitivity to the study drug; pregnancy; dialysis; galactose intolerance; or at the decision of the study investigator.

\section{Variable Definition}

The primary safety outcome was the incidence rate of $\mathrm{AE}$ during the 12-month study period. Data from each visit were analyzed according to the Common Toxicity Criteria for Adverse Events (CTCAE), v4.03, and severity of patientreported symptoms were reported according to the Spilker classification. The severity and outcome of AE, and its association with the study drug were also assessed. Events were defined as adverse drug reactions (ADR) if there was a "certain," "probable," "possible," “conditional," or "not 


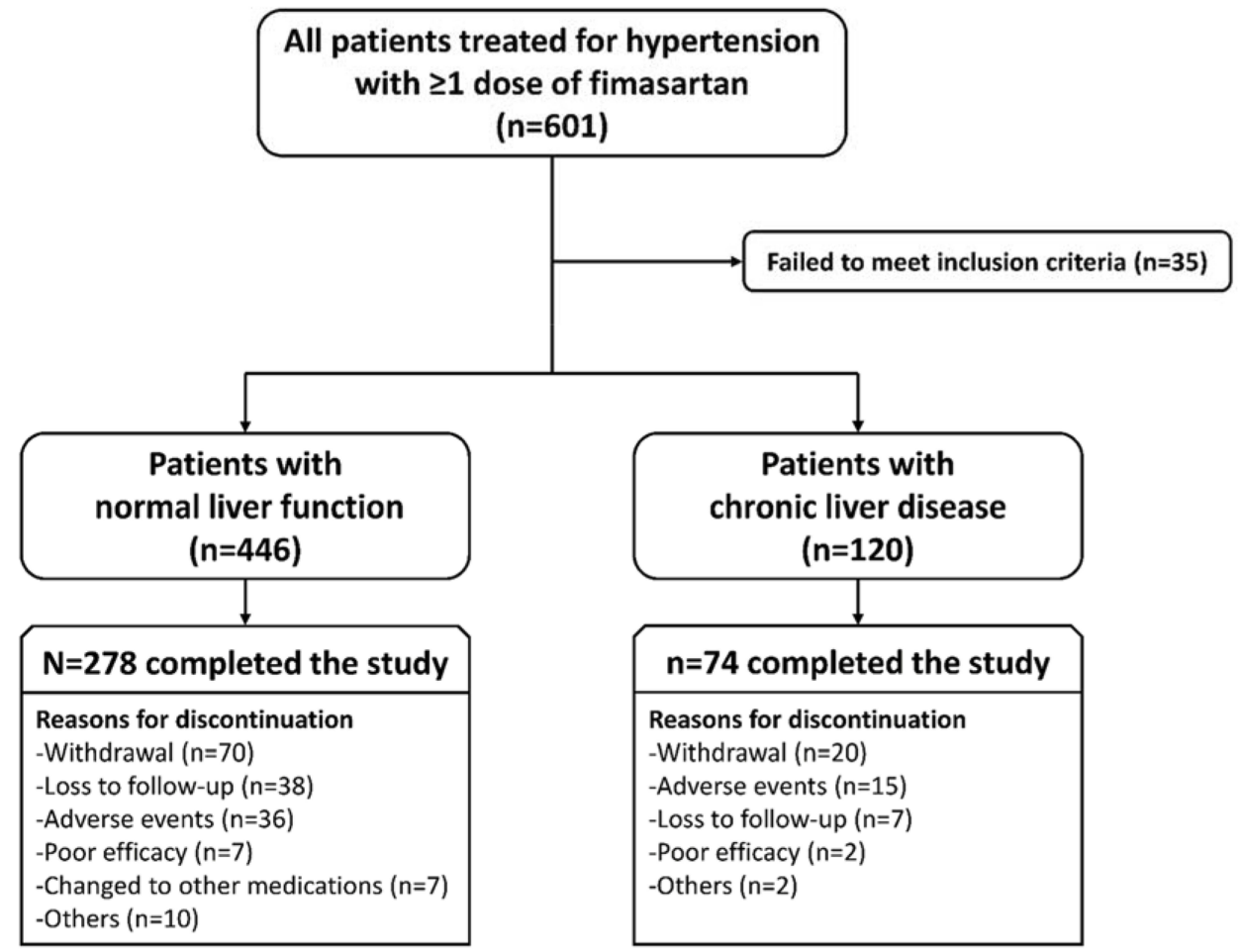

Figure I Study design.

classifiable" association with the study drug. All AE and ADR were recorded and coded using Medical Dictionary for Regulatory Activities (MedDRA) version 19.0 and classified according to system organ class (SOC) and preferred terms (PT). Abnormalities in liver function enzymes, specifically aspartate transaminase (AST), alanine transaminase (ALT), alkaline phosphatase (ALP), and total bilirubin, were recorded at each visit to assess for drug-induced liver injury. ${ }^{16}$ Treatment persistence and changes in blood pressure were also recorded for analysis. Criteria fulfilling the Hy's law were investigated to assess whether the patients were at high risk of fatal drug-induced liver injury. ${ }^{17}$

Tests for liver function enzymes were performed at each follow-up visit to assess liver injury after the use of the study drug. Abnormal test results were categorized as follows: (1) acute hepatocellular liver injury defined by alanine transaminase (ALT) $>2 \times$ upper limit of normal (ULN) or ALT/alkaline phosphatase (AP) ratio $\geq 5$, (2) acute cholestatic injury defined as AP $>2 \times$ ULN or ALT/AP $\leq 2$, and (3) mixed hepatic injury with intermediate clinical and biological characteristics between hepatocellular and cholestatic patterns.

\section{Statistics}

The total sample size was calculated using the "Rule of three,"18 a frequently used method for assessment of a specific adverse event. A study population of 600 patients had the power to evaluate an adverse event with an incidence of $0.5 \%$, at a level of significance of $95 \%$.

Continuous variables are described as mean \pm standard deviation or median and interquartile range, and categorical variables as numbers and percentages. The chi-square test or Fisher's exact test is used for comparison of categorical variables, and the independent $t$-test or the Wilcoxon's ranksum test is used for continuous variables. All analyses are two-sided, and p-values $<0.05$ are considered statistically significant. Statistical analyses were performed using SAS version 9.3 (SAS Institute, Cary, North Carolina).

\section{Results}

\section{Study Population}

A total of 601 patients were screened for study enrollment at three participating centers in Korea. After excluding patients who failed to meet predefined criteria, 566 patients were categorized into two groups according to the presence of underlying liver disease. Among 446 patients without prior liver disease, 278 (62.3\%) completed the 12-month study, and $168(37.7 \%)$ discontinued prematurely. The main reasons for discontinuation were withdrawal of consent (70, $15.7 \%)$, loss to follow-up $(38,8.5 \%)$ and $\mathrm{AE}(36,8.1 \%)$. 
For 120 patients with chronic liver disease, 74 (61.7\%) completed the 12-month study, with reasons for discontinuation being withdrawal of consent, $\mathrm{AE}$, and loss-to follow up in $20(16.7 \%), 15(12.5 \%)$ and $7(5.8 \%)$ patients, respectively. In the total study population, mean age was $59.8 \pm$ 11.8 years, and $56.5 \%$ were male with a median 3.0 year [IQR 0-10.0 years] duration of HTN. Co-morbid conditions such as diabetes mellitus (DM), dyslipidemia and chronic kidney disease were prevalent in $18.9 \%, 10.4 \%$ and $9.2 \%$ of the patients. Frequent co-administered drugs were lipidmodifying agents $(223,39.4 \%)$, calcium-channel blockers (186, 32.9\%) and antithrombotic agents (179, 31.6\%). Baseline demographics and clinical details of the study groups are summarized in Table 1.

\section{Adverse Events/Adverse Drug Reactions}

Overall, $347 \mathrm{AE}$ in 179 patients (31.6\%) were reported during the study period. The severity was mostly mild (270/347, $77.8 \%)$ to moderate $(66 / 347,19.0 \%)$ in degree. Dizziness $(25 / 566,4.4 \%)$ and headaches $(16 / 566,2.8 \%)$ were frequently reported events. At the end of the study, 295 $(85.0 \%)$ events had fully recovered or were in recovery, while 42 (12.1\%) events were considered to be persistent.
Most events were determined to have no association with fimasartan treatment $(278 / 347,80.1 \%)$. Although there was a statistically higher proportion of patients experiencing AE in the group with chronic liver disease $(42.5 \%$ vs $28.7 \%$ ), there was no significant difference in severity $(p=0.158)$. In the whole study population, there were 39 serious adverse events (SAE) reported in 33 patients (5.8\%), but none were determined to be associated with fimasartan. Finally, there were no deaths or serious adverse drug reactions (SADR) reported during the study period.

Among 347 reported AE, 69 cases in 57 patients (10.1\%) were considered to have a relationship with the study drug and defined as ADR. The events were all mild to moderate in severity, with no severe cases. Patients without prior liver disease showed a significantly higher recovery rate and lower discontinuation rate compared with those with underlying liver disease. Frequently occurring $(\geq 1 \%) \mathrm{AE}$ and ADR are summarized by SOC and presented in Table 2 .

In multivariate logistic regression analysis, chronic liver disease (OR 2.01, 95\% CI 1.29-3.12, $\mathrm{p}=0.002$ ), female sex (OR 1.49, 95\% CI 1.02-2.18, $\mathrm{p}=0.041)$ and old age (OR $1.12,95 \%$ CI $1.03-1.22, \mathrm{p}=0.008$ for every 5 -year increase) were independent predictors for developing $\mathrm{AE}$ in the whole

Table I Patient Characteristics According to Baseline Liver Function

\begin{tabular}{|c|c|c|c|c|}
\hline & Total $(n=566)$ & Normal Liver Function $(n=446)$ & Chronic Liver Disease $(n=\mid 20)$ & p-value \\
\hline Age (years) & $59.8 \pm 11.8$ & $59.9 \pm 12.4$ & $59.3 \pm 8.9$ & 0.308 \\
\hline Sex (male), n (\%) & $320(56.5)$ & $233(52.2)$ & $87(72.5)$ & $<0.001$ \\
\hline $\mathrm{BMI}\left(\mathrm{kg} / \mathrm{m}^{2}\right)$ & $25.4 \pm 3.3$ & $25.4 \pm 3.4$ & $25.1 \pm 2.9$ & 0.480 \\
\hline Duration of HTN (yr, [IQR]) & $3.0[0,10.0]$ & $4.0[0.1,10.1]$ & $1.0[0,8.0]$ & $<0.001$ \\
\hline DM & $107(18.9)$ & $85(19.1)$ & $22(18.3)$ & 0.857 \\
\hline Dyslipidemia & $59(10.4)$ & $58(13.0)$ & $\mathrm{I}(0.8)$ & $<0.001$ \\
\hline Chronic Kidney disease & $52(9.2)$ & $49(11.0)$ & $3(2.5)$ & 0.004 \\
\hline \multicolumn{5}{|l|}{ Medications } \\
\hline - Lipid modifying agents & $223(39.4)$ & $204(45.7)$ & $19(15.8)$ & $<0.001$ \\
\hline - Calcium channel blockers & $186(32.9)$ & $163(36.6)$ & $23(19.2)$ & $<0.001$ \\
\hline - Antithrombotic agents & $179(3 \mid .6)$ & $166(37.2)$ & $13(10.8)$ & $<0.001$ \\
\hline \multicolumn{5}{|l|}{ Laboratory tests } \\
\hline - AST (IU/L) & $24.9 \pm 9.0$ & $24.1 \pm 8.2$ & $28.3 \pm 11.2$ & $<0.001$ \\
\hline - ALT (IU/L) & $25.3 \pm 12.9$ & $25.0 \pm 12.9$ & $26.9 \pm 13.1$ & 0.184 \\
\hline - ALP (IU/L) & $71.2 \pm 23.1$ & $71.0 \pm 23.3$ & $72.1 \pm 22.6$ & 0.662 \\
\hline - Total bilirubin (mg/dL) & $0.9 \pm 0.4$ & $0.8 \pm 0.4$ & $1.0 \pm 0.3$ & 0.001 \\
\hline HBsAg (+), n (\%) & $76(13.4)$ & - & $76(63.3)$ & \\
\hline HCV RNA (+), n (\%) & $13(2.3)$ & - & $13(10.8)$ & \\
\hline Liver Cirrhosis & $51(9.0)$ & & $51(42.5)$ & \\
\hline Hepatocellular carcinoma & $21(3.7)$ & & $21(17.5)$ & \\
\hline
\end{tabular}

Abbreviations: HTN, hypertension; DM, diabetes mellitus; AST, aspartate transaminase; IU, international unit; ALT, alanine transaminase; ALP, alkaline phosphatase; $\mathrm{HBsAg}$, hepatitis b virus surface antigen; $\mathrm{HCV}$, hepatitis c virus. 
Table 2 Frequency of Adverse Events and Adverse Drug Reactions

\begin{tabular}{|c|c|c|c|c|c|c|c|c|}
\hline & \multicolumn{4}{|c|}{ Adverse Events } & \multicolumn{4}{|c|}{ Adverse Drug Reactions } \\
\hline & $\begin{array}{l}\text { Total } \\
(n=566)\end{array}$ & $\begin{array}{l}\text { Normal Liver } \\
\text { Function } \\
(n=446)\end{array}$ & $\begin{array}{l}\text { Chronic Liver } \\
\text { Disease } \\
(n=\mid 20)\end{array}$ & p-value & $\begin{array}{l}\text { Total } \\
(n=566)\end{array}$ & $\begin{array}{l}\text { Normal Liver } \\
\text { Function } \\
(n=446)\end{array}$ & $\begin{array}{l}\text { Chronic Liver } \\
\text { Disease } \\
(n=\mid 20)\end{array}$ & p-value \\
\hline $\begin{array}{l}\text { Number of patients ( } \mathrm{n}, \%) \\
\text { Number of events (cases) } \\
\text { Serious events (cases, \%) }\end{array}$ & $\begin{array}{l}179(31.6) \\
347 \\
39(11.2)\end{array}$ & $\begin{array}{l}128(28.7) \\
247 \\
25(10.1)\end{array}$ & $\begin{array}{l}51(42.5) \\
100 \\
14(14.0)\end{array}$ & 0.004 & $\begin{array}{l}57(10.1) \\
69 \\
0(0.0)\end{array}$ & $\begin{array}{l}34(7.6) \\
4 I \\
0(0.0)\end{array}$ & $\begin{array}{l}23(19.2) \\
28 \\
0(0.0)\end{array}$ & $<0.001$ \\
\hline $\begin{array}{l}\text { Severity (cases, \%) } \\
\text { - Mild } \\
\text { - Moderate } \\
\text { - Severe }\end{array}$ & $\begin{array}{l}270(77.8) \\
66(19.0) \\
11(3.2)\end{array}$ & $\begin{array}{l}194(78.5) \\
48(19.4) \\
5(2.0)\end{array}$ & $\begin{array}{l}76(76.0) \\
18(18.0) \\
6(6.0)\end{array}$ & 0.158 & $\begin{array}{l}58(84.1) \\
11(15.9) \\
0(0.0)\end{array}$ & $\begin{array}{l}34(82.9) \\
7(17.1) \\
0(0.0)\end{array}$ & $\begin{array}{l}24(85.7) \\
4(14.3) \\
0(0.0)\end{array}$ & 0.756 \\
\hline $\begin{array}{l}\text { Outcome (cases, \%) } \\
\text { - Recovery } \\
\text { - Persistent } \\
\text { - Unknown }\end{array}$ & $\begin{array}{l}295(85.0) \\
42(12.1) \\
10(2.9)\end{array}$ & $\begin{array}{l}217(87.9) \\
21(8.5) \\
9(3.6)\end{array}$ & $\begin{array}{l}78(78.0) \\
21(21.0) \\
1(1.0)\end{array}$ & 0.003 & $\begin{array}{l}53(76.8) \\
13(18.8) \\
3(4.3)\end{array}$ & $\begin{array}{l}34(82.9) \\
4(9.8) \\
3(7.3)\end{array}$ & $\begin{array}{l}19(67.9) \\
9(32.1) \\
0(0.0)\end{array}$ & 0.031 \\
\hline Study drug discontinuation & $63(11.1)$ & $44(9.9)$ & $19(15.8)$ & 0.065 & $43(7.6)$ & $25(5.6)$ & $18(15.0)$ & 0.001 \\
\hline $\begin{array}{l}\text { Classification (patients, \%) } \\
\text { - Nervous system disorders } \\
\text { - Laboratory abnormalities } \\
\text { - Gastrointestinal disorders } \\
\text { - Infections } \\
\text { - General disorders } \\
\text { - Skin disorders } \\
\text { - Vascular disorders } \\
\text { - Musculoskeletal disorders } \\
\text { - Respiratory disorders } \\
\text { - Injury } \\
\text { - Neoplasms } \\
\text { - Eye disorders } \\
\text { - Renal disorders } \\
\text { - Reproductive system disorders } \\
\text { - Metabolic disorders } \\
\text { - Others }\end{array}$ & $\begin{array}{l}50(8.8) \\
34(6.0) \\
30(5.3) \\
27(4.8) \\
20(3.5) \\
18(3.2) \\
15(2.7) \\
14(2.5) \\
13(2.3) \\
14(2.5) \\
13(2.3) \\
9(1.6) \\
7(1.2) \\
7(1.2) \\
6(1.1) \\
18(3.2)\end{array}$ & $\begin{array}{l}40(9.0) \\
27(6.1) \\
20(4.5) \\
18(4.0) \\
13(2.9) \\
12(2.7) \\
10(2.2) \\
11(2.5) \\
10(2.2) \\
11(2.5) \\
4(0.9) \\
8(1.8) \\
6(1.4) \\
4(0.9) \\
3(0.7) \\
13(2.9)\end{array}$ & $\begin{array}{l}10(8.3) \\
7(5.8) \\
10(8.3) \\
9(7.5) \\
7(5.8) \\
6(5.0) \\
5(4.2) \\
3(2.5) \\
3(2.5) \\
3(2.5) \\
9(7.5) \\
1(0.8) \\
1(0.8) \\
3(2.5) \\
3(2.5) \\
5(4.2)\end{array}$ & & $\begin{array}{l}24(4.2) \\
14(2.5) \\
4(0.7) \\
0(0.0) \\
5(0.8) \\
6(1.1) \\
10(1.8) \\
0(0.0) \\
0(0.0) \\
0(0.0) \\
0(0.0) \\
0(0.0) \\
3(4.3) \\
0(0.0) \\
0(0.0) \\
2(0.4)\end{array}$ & $\begin{array}{l}16(3.6) \\
11(2.5) \\
2(0.5) \\
0(0.0) \\
2(0.5) \\
2(0.5) \\
5(1.1) \\
0(0.0) \\
0(0.0) \\
0(0.0) \\
0(0.0) \\
0(0.0) \\
3(7.3) \\
0(0.0) \\
0(0.0) \\
0(0.0)\end{array}$ & $\begin{array}{l}8(6.7) \\
3(2.5) \\
2(1.7) \\
0(0.0) \\
3(2.5) \\
4(3.3) \\
5(4.2) \\
0(0.0) \\
0(0.0) \\
0(0.0) \\
0(0.0) \\
0(0.0) \\
0(0.0) \\
0(0.0) \\
0(0.0) \\
2(1.7)\end{array}$ & \\
\hline
\end{tabular}

study population (Table 3). History of prior liver disease was also an independent predictor of ADR, as shown in Supplemental Table 1. In post hoc analysis, the association of underlying liver disease and $\mathrm{AE}$ was not significantly different between exploratory subgroups (Figure 2).

Among patients with chronic liver disease, no differences were observed in the incidence of $\mathrm{AE}$ according to different liver conditions. In detail, among 51 patients with liver cirrhosis, 39.2\% experienced AE, compared with $44.9 \%$ in 69 patients without cirrhosis $(\mathrm{p}=0.532)$. For 21 patients with hepatocellular carcinoma, $47.6 \%$ reported events, compared with $41.4 \%$ in those without malignancy $(p=0.601)$. There were also no significant differences in ADR ( $\mathrm{p}=0.565$ for cirrhosis, $\mathrm{p}=0.532$ for $\mathrm{HCC}$ ) or discontinuations ( $\mathrm{p}=0.330$ for cirrhosis, $\mathrm{p}=0.126$ for HCC).

\section{Events Associated with Liver Function}

Laboratory tests were performed at 3-month intervals to assess changes in liver function after fimasartan treatment. In patients with chronic liver disease, serum AST and total bilirubin levels were significantly higher at baseline (Table 1), and the difference persisted throughout the study period (Table 4). During follow-up, liver function enzyme abnormalities were more frequently observed in patients with chronic liver disease $(10.8 \%$ [13] vs $3.6 \%$ [16], $p=0.001)$. In detail, there were 7 cases of hepatocellular injury, 1 case of cholestatic injury, and 5 cases of mixed type injury observed in the chronic liver disease group, whereas 14 cases of hepatocellular injury, 1 case of cholestatic injury, and 1 case of mixed type injury were observed in the normal liver function group. There were no significant differences in discontinuation rates $(2.5 \%$ [3] vs 
Table 3 Multivariate Regression Analysis for Development of Adverse Events and Adverse Drug Reactions

\begin{tabular}{|l|l|l|l|l|}
\hline \multirow{2}{*}{} & \multicolumn{3}{|l|}{ Univariate Analysis } & \multicolumn{2}{l|}{$\begin{array}{l}\text { Multivariate } \\
\text { Analysis }\end{array}$} \\
\cline { 2 - 5 } & $\begin{array}{l}\text { OR } \\
{[95 \% \mathrm{CI}]}\end{array}$ & p-value & $\begin{array}{l}\text { OR } \\
{[95 \% \mathrm{CI}]}\end{array}$ & p-value \\
\hline $\begin{array}{l}\text { Age (for every 5-year } \\
\text { increase) }\end{array}$ & $\begin{array}{l}1.13 \\
{[1.05-1.23]}\end{array}$ & 0.002 & $\begin{array}{l}1.12 \\
{[1.03-1.22]}\end{array}$ & 0.008 \\
\hline Female sex & $\begin{array}{l}1.45 \\
{[1.01-2.07]}\end{array}$ & 0.042 & $\begin{array}{l}1.49 \\
{[1.02-2.18]}\end{array}$ & 0.041 \\
\hline $\begin{array}{l}\text { BMI (for every I kg/m } \\
\text { increase) }\end{array}$ & $\begin{array}{l}1.02 \\
{[0.97-1.08]}\end{array}$ & 0.406 & & \\
\hline DM & $\begin{array}{l}0.89 \\
{[0.57-1.40]}\end{array}$ & 0.618 & & \\
\hline CKD & $\begin{array}{l}2.06 \\
{[1.01-4.20]}\end{array}$ & 0.048 & & \\
\hline $\begin{array}{l}\text { Elevated AST or ALT }(\geq \\
40 \text { IU) }\end{array}$ & $\begin{array}{l}3.18 \\
{[1.19-8.47]}\end{array}$ & 0.021 & & \\
\hline Chronic liver disease & $\begin{array}{l}1.84 \\
{[1.21-2.78]}\end{array}$ & 0.004 & $\begin{array}{l}2.01 \\
{[1.29-3.12]}\end{array}$ & 0.002 \\
\hline
\end{tabular}

Notes: Multivariate logistic regression analysis performed with age, sex, BMI, DM, CKD, elevated liver enzyme tests, and chronic liver disease as independent variables.

Abbreviations: $\mathrm{BMI}$, body mass index; OR, hazard ratio; $\mathrm{Cl}$, confidence interval; DM, diabetes mellitus; CKD, chronic kidney disease; AST, aspartate transaminase; ALT, alanine transaminase; IU, international units.

$1.1 \%$ [5], $\mathrm{p}=0.376$ ) due to abnormal liver function, and no cases fulfilling the Hy's law criteria.

\section{Efficacy and Persistence}

After 12 months, 358 patients continued treatment with Fimasartan (285 with normal liver function and 73 with chronic liver disease). The mean change in SBP was not significantly different between groups after adjusting for baseline values (least square [LS] mean change $-6.57 \pm 0.80$ $\mathrm{mmHg}$ for normal liver function group; $-7.65 \pm 1.59 \mathrm{mmHg}$ for chronic liver disease group; $\mathrm{p}=0.546$ ). The reduction in $\mathrm{BP}$ mostly occurred in the initial 6 months, after which BP values became stable and persisted throughout the study period. While discontinuation rates increased in the early study period, the rate of increase decreased after 6 months, showing a 1-year cumulative rate of $37.7 \%$ and $38.3 \%$ for each group (Figure 3 ).

\section{Discussion}

The current study evaluated the long-term safety profile of fimasartan in the treatment of HTN by following-up 566 patients for up to 12 months. Although previous clinical studies have reported excellent tolerability of fimasartan, ${ }^{9,11,19}$ there has been no scientific evidence backing its long-term safety. Furthermore, there have been concerns that fimasartan might be related to liver toxicity due to its predominant hepatobiliary excretion. ${ }^{13,20,21}$ The results of this prospective study provide reliable evidence that fimasartan could be a safe choice for long-term treatment of HTN, regardless of underlying liver disease.

To the best of our knowledge, this is the first study to assess the long-term outcome of fimasartan treatment. The rate of $\mathrm{AE}$ and ADR in the current study is comparable to that of the previous Phase III trial (AE rate of $32.6 \%$ and ADR rate of $7.8 \%) .{ }^{11}$ The scope of events is also similar to that of a previous randomized controlled trial, showing headache, respiratory infection, dizziness and fatigue as frequent events. ${ }^{11}$

In previous trials, ARB have mostly shown better tolerability than ACE inhibitor, ${ }^{22,23}$ and discontinuation rates of ARB in major trials have been relatively low. In a study comparing the efficacy and safety of olmesartan, losartan, and valsartan in patients treated for essential HTN, Giles et al reported a discontinuation rate of $16.9 \%, 13.5 \%$, and $10.3 \%$, respectively. ${ }^{24}$ In a trial evaluating the 1-year persistence rate of major classes of antihypertensive medications, valsartan showed a persistence rate of $69.4 \% .{ }^{25}$ Although our study showed a slightly lower persistence rate (62.1\%) compared to other previous studies, the difference may have been due to a broader range of real-world patients included in the study. Moreover, the proportion of discontinuation due to $\mathrm{AE}$ was low (11.1\%).

HTN is difficult to control with a single medication, and add-on therapy is common in clinical practice. HTN also frequently coexists with other morbidities such as dyslipidemia or diabetes, requiring even more medications. Furthermore, current guidelines on HTN recommend combination therapy as an initial strategy for most patients. ${ }^{26}$ It is well known that the number of drugs that a patient takes is closely correlated to increased risk of adverse events and lower compliance. ${ }^{27}$ In the UK, a retrospective analysis showed that $28.5 \%$ of patients newly treated for HTN stopped medications at 1-year, and the median time to cessation was 3.1 years. ${ }^{25}$ Although randomized controlled trials have a high level of evidence, they tend to control other concomitant drugs and offer an ideal therapeutic environment. In our study, over $30 \%$ of the participants were using lipid-modifying agents, calcium-channel blockers, and antithrombotic agents such as aspirin. The results of our study may better represent the real-world environment of treating HTN, providing valuable data on the safety profile of fimasartan use in Korean HTN patients. 


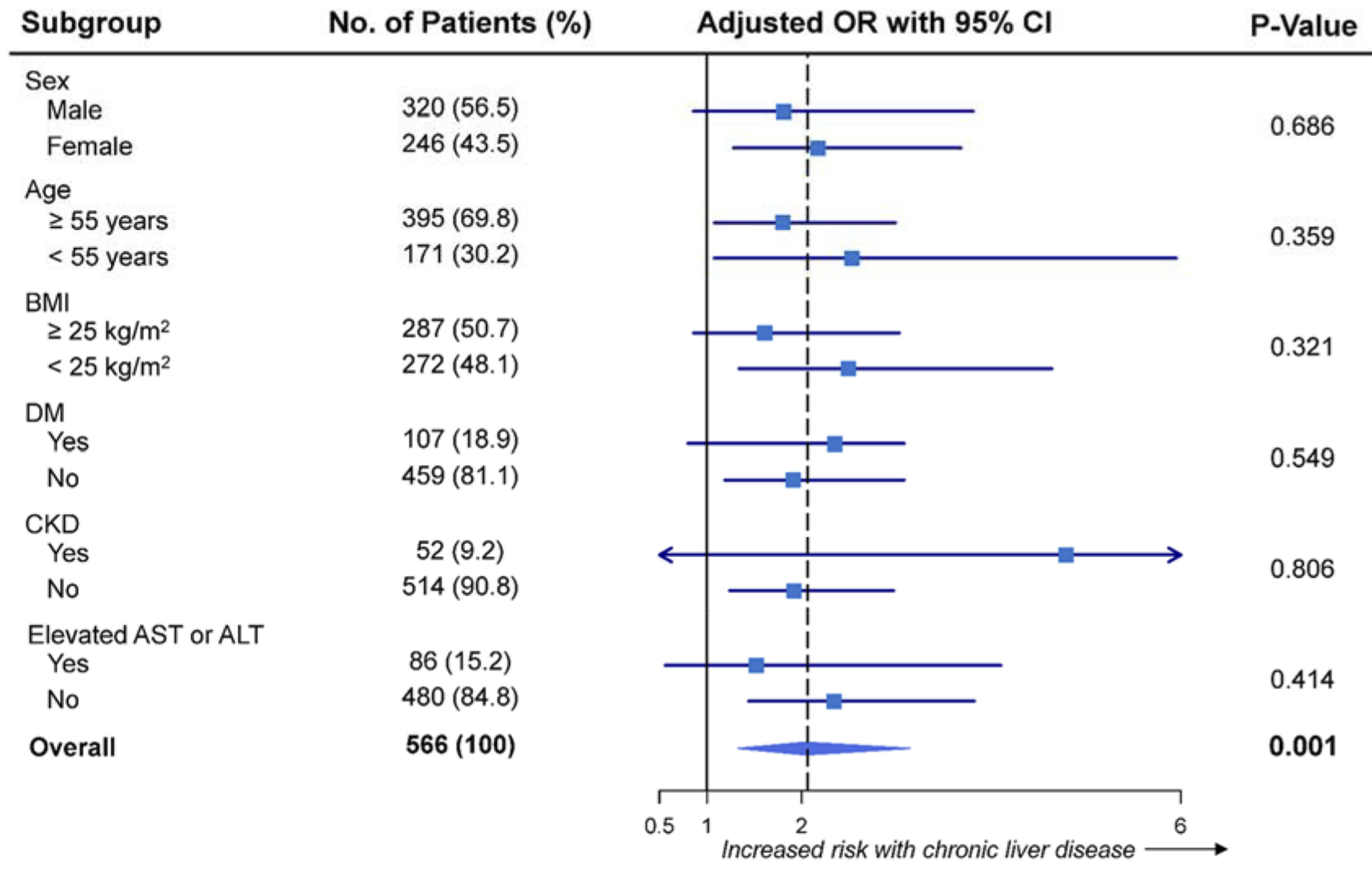

Figure 2 The risk of adverse events according to chronic liver disease is not significantly different between exploratory subgroups. Abbreviations: $\mathrm{OR}$, odds ratio; $\mathrm{Cl}$, confidence interval.

Side effects are frequently reported in the treatment of HTN. It has been reported that $35 \%$ of patients starting treatment stop medications during the first 6 months, and half of them are due to $\mathrm{AE}{ }^{28}$ According to a 5 -year prospective study on 5485 newly treated HTN patients, $9.3 \%$ stopped treatment due to either definite or probable ADR. ${ }^{29}$ Common side effects of ARB include dizziness, headache and hyperkalemia. Liver toxicity after ARB use is a rare, but serious event, and there have been individual case reports after the use of losartan, ${ }^{30,31}$ irbesartan, ${ }^{20}$ candesartan, ${ }^{21}$ and valsartan. ${ }^{32}$ Fimasartan has also been reported to have caused liver damage in a patient who had tolerated previous ARB use. ${ }^{13}$ According to previous

Table 4 Changes in Liver Function Enzymes

\begin{tabular}{|c|c|c|c|c|c|c|c|c|c|}
\hline & \multicolumn{4}{|c|}{ Normal Liver Function $(n=446)$} & \multicolumn{4}{|c|}{ Chronic Liver Disease $(n=\mid 20)$} & \multirow[t]{3}{*}{ p-value } \\
\hline & AST & ALT & ALP & Bil & AST & ALT & ALP & Bil & \\
\hline Month $3^{\mathrm{a}}$ & $25.1 \pm 12.1$ & $26.9 \pm 19.0$ & $69.4 \pm 18.7$ & $0.8 \pm 0.3$ & $30.9 \pm 15.6^{c}$ & $29.4 \pm 14.1$ & $69.6 \pm 21.0$ & $0.9 \pm 0.3^{c}$ & \\
\hline Month $12^{b}$ & $24.9 \pm 10.7$ & $25.7 \pm 14.9$ & $64.5 \pm 18.3$ & $0.8 \pm 0.3$ & $29.8 \pm 16.9^{c}$ & $29.6 \pm 18.7$ & $66.5 \pm 25.5$ & $1.0 \pm 0.4^{c}$ & \\
\hline $\begin{array}{l}\text { Patients with abnormal liver } \\
\text { function enzymes }\end{array}$ & \multicolumn{4}{|l|}{$16(3.6)$} & \multicolumn{4}{|l|}{$13(10.8)$} & 0.001 \\
\hline Hepatocellular injury & \multicolumn{4}{|l|}{$14(3.1)$} & \multicolumn{4}{|l|}{$7(5.8)$} & \\
\hline Cholestatic injury & \multicolumn{4}{|l|}{$\mathrm{I}(0.2)$} & \multicolumn{4}{|l|}{$\mathrm{I}(0.8)$} & \\
\hline Mixed type & \multicolumn{4}{|l|}{ I $(0.2)$} & \multicolumn{4}{|l|}{$5(4.2)$} & \\
\hline Discontinuations & \multicolumn{4}{|l|}{$5(1.1)$} & \multicolumn{4}{|l|}{$3(2.5)$} & 0.376 \\
\hline
\end{tabular}

Notes: Results of liver function tests were available in ${ }^{\mathrm{a}} 463$ and ${ }^{\mathrm{b}} 300$ patients. ${ }^{\mathrm{c}}$ Significant increase in levels compared to patients with normal liver function ( $\left.p<0.05\right)$. Abbreviations: AST, aspartate transaminase; ALT, alanine transaminase; ALP, alkaline phosphatase; Bil, total bilirubin. 


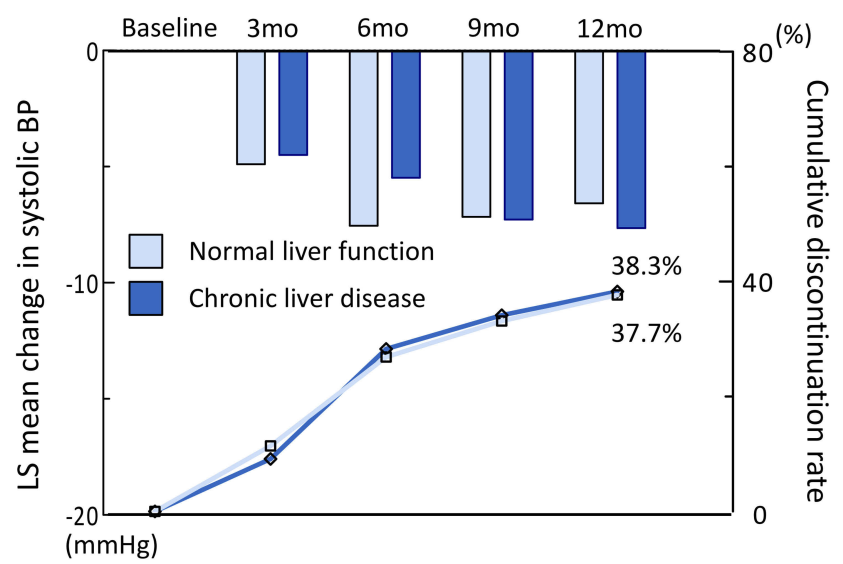

Figure 3 Changes in systolic blood pressure and discontinuation rates according to baseline liver disease.

literature, most liver damages brought on by ARB were selflimiting, mild to moderate in severity, and rarely needed discontinuation or dose adjustment. In our study, only $3.6 \%$ of patients with normal baseline liver function experienced elevations in liver enzymes during follow-up, with $1.1 \%$ discontinuing therapy as a result. The incidence of elevations was more frequent in the group with chronic liver disease, but there were no cases serious enough to fulfill the Hy's law, a criterion predicting fatal drug-induced liver injuries. In addition, there were no differences in events according to the specific nature of the baseline liver disease. All cases were asymptomatic and transient, leading to only a small number of discontinuations. Although chronic liver disease, along with old age, female sex and history of prior liver disease were independent predictors in regression analysis, most cases were mild to moderate in intensity, and no serious events were reported. The results of our study suggest that long-term use of fimasartan is not associated with major liver toxicity, especially in those without prior liver disease. For patients with chronic liver disease, fimasartan use was generally well tolerated, although extra caution should be taken when used on old, female patients due to the possibility of increased risk of AE. Liver function enzymes should also be followed-up more thoroughly in patients with underlying liver disease.

The limitations of the study are as follows: The study was designed as a single-arm, open-label, observational study, which could have made it susceptible to bias related to knowledge of treatment. It also lacked a placebo control group. In addition, as all patients receiving $\geq 1$ dose of the study drug were enrolled in the safety analysis, the persistence rate of fimasartan might have been underestimated. The results of post hoc regression analyses also should be interpreted with caution. Further randomized controlled trials would be needed to properly assess the risk factors associated with the development of $\mathrm{AE}$

\section{Conclusion}

In conclusion, the long-term use of fimasartan for treatment of HTN was associated with a low rate of AE in patients with no underlying liver disease. The rate of $\mathrm{AE}$ was increased in those with chronic liver disease, but the drug is well tolerated. With a persistence rate comparable to other classes of antihypertensive drugs, fimasartan can be suitable for long-term treatment of essential HTN.

\section{Data Sharing Statement}

ndividual participant data that underlie the results reported in this article will be available on request, after deidentification, to researchers who provide a methodologically sound proposal. Requests should be sent to the corresponding author.

\section{Acknowledgments}

This study was sponsored by Boryung Pharmaceutical Co. Ltd (Seoul, Korea). The sponsor supported the funding source and participated in the study. The study was designed, conducted, and written by the authors. Independent external monitoring groups (CRSCube, Seoul, Korea; LSK Global PS, Seoul, Korea) were involved in the collection and analysis of data.

\section{Disclosure}

The authors report no conflicts of interest in this work.

\section{References}

1. WHO. Global Brief on Hypertension: Silent Killer, Global Public Health Crisis; 2013.

2. Whelton PK, Carey RM, Aronow WS, et al. 2017 ACC/AHA/AAPA/ $\mathrm{ABC} / \mathrm{ACPM} / \mathrm{AGS} / \mathrm{APhA} / \mathrm{ASH} / \mathrm{ASPC} / \mathrm{NMA} / \mathrm{PCNA}$ guideline for the prevention, detection, evaluation, and management of high blood pressure in adults: a Report of the American College of Cardiology/American Heart Association Task Force on Clinical Practice Guidelines. J Am Coll Cardiol. 2018;71(19):e127-e248. doi:10.1016/j.jacc.2017.11.006

3. Lee H, Park S, Kim HC. Temporal and geospatial trends of hypertension management in Korea: a nationwide study 2002-2016. Korean Circ J. 2019;49(6):514-527. doi:10.4070/kcj.2018.0358

4. Shah SJ, Stafford RS. Current trends of hypertension treatment in the United States. Am J Hypertens. 2017;30(10):1008-1014. doi:10.1093/ajh/ hpx085

5. Kim HC, Cho MC; Korean Society H, Hypertension Epidemiology Research Working G. Korea hypertension fact sheet 2018. Clin Hypertens. 2018;24:13. doi:10.1186/s40885-018-0098-0

6. Kim I, Park CS, Lee HY. Angiotensin II Type 1 receptor blocker, fimasartan, reduces vascular smooth muscle cell senescence by Inhibiting the CYR61 signaling pathway. Korean Circ J. 2019;49 (7):615-626. doi:10.4070/kcj.2018.0379 
7. Lee HY, Oh BH. Fimasartan: a new angiotensin receptor blocker. Drugs. 2016;76(10):1015-1022. doi:10.1007/s40265-016-0592-1

8. Kim JH, Lee JH, Paik SH, Kim JH, Chi YH. Fimasartan, a novel angiotensin II receptor antagonist. Arch Pharm Res. 2012;35 (7):1123-1126. doi:10.1007/s12272-012-0700-z

9. Lee HY, Kim CH, Song JK, et al. 24-Hour blood pressure response to lower dose $(30 \mathrm{mg})$ fimasartan in Korean patients with mild to moderate essential hypertension. Korean J Intern Med. 2017;32 (6): 1025-1036. doi:10.3904/kjim.2016.094

10. Lee H, Yang HM, Lee HY, et al. Efficacy and tolerability of once-daily oral fimasartan 20 to $240 \mathrm{mg} / \mathrm{d}$ in Korean patients with hypertension: findings from Two Phase II, randomized, double-blind, placebo-controlled studies. Clin Ther. 2012;34(6):1273-1289.

11. Lee SE, Kim YJ, Lee HY, et al. Efficacy and tolerability of fimasartan, a new angiotensin receptor blocker, compared with losartan (50/ $100 \mathrm{mg}$ ): a 12-week, Phase III, multicenter, prospective, randomized, double-blind, parallel-group, dose escalation clinical trial with an optional 12-week extension phase in adult Korean patients with mild-to-moderate hypertension. Clin Ther. 2012;34(3):552-568, 568 e551-e559. doi:10.1016/j.clinthera.2012.01.024

12. Chi YH, Lee H, Paik SH, et al. Safety, tolerability, pharmacokinetics, and pharmacodynamics of fimasartan following single and repeated oral administration in the fasted and fed states in healthy subjects. $\mathrm{Am}$ J Cardiovasc Drugs. 2011;11(5):335-346. doi:10.2165/11593840000000000-00000

13. Park DH, Yun GY, Eun HS, et al. Fimasartan-induced liver injury in a patient with no adverse reactions on other types of angiotensin II receptor blockers: a case report. Medicine (Baltimore). 2017;96(47): e8905. doi:10.1097/MD.0000000000008905

14. Lee HY, Shin J, Kim GH, et al. 2018 Korean Society of Hypertension Guidelines for the management of hypertension: part II-diagnosis and treatment of hypertension. Clin Hypertens. 2019;25:20. doi:10.1186/ s40885-019-0124-x

15. Kim HC, Ihm SH, Kim GH, et al. 2018 Korean Society of Hypertension guidelines for the management of hypertension: part I-epidemiology of hypertension. Clin Hypertens. 2019;25:16. doi:10.1186/s40885-019-0121-0

16. Hoofnagle JH, Björnsson ES. Drug-induced liver injury — types and phenotypes. $N$ Engl J Med. 2019;381(3):264-273. doi:10.1056/ NEJMra1816149

17. Robles-Diaz M, Lucena MI, Kaplowitz N, et al. Use of Hy's law and a new composite algorithm to predict acute liver failure in patients with drug-induced liver injury. Gastroenterology. 2014;147(1):109118 e105. doi:10.1053/j.gastro.2014.03.050

18. United States. Congress. Office of Technology Assessment. Postmarketing Surveillance of Prescription Drugs. Washington, D.C.: Congress of the United States For sale by the Supt. of Docs., U.S. G.P. O.; 1982.

19. Youn JC, Ihm SH, Bae JH, et al. Efficacy and safety of 30-mg fimasartan for the treatment of patients with mild to moderate hypertension: an 8-week, multicenter, randomized, double-blind, phase III clinical study. Clin Ther. 2014;36(10):1412-1421. doi:10.1016/j. clinthera.2014.07.004
20. Andrade RJ, Lucena MI, Fernandez MC, et al. Cholestatic hepatitis related to use of irbesartan: a case report and a literature review of angiotensin II antagonist-associated hepatotoxicity. Eur $J$ Gastroenterol Hepatol. 2002;14(8):887-890. doi:10.1097/000427 37-200208000-00014

21. Lammel-Lindemann JA, Flores-Villalba E, Martagon AJ, DeObesoGonzalez E, Puente-Gallegos F. Noncholestatic acute hepatocellular injury following candesartan administration. Br J Clin Pharmacol. 2018;84(1):204-207. doi:10.1111/bcp.v84.1

22. Visser LE, Stricker BH, van der Velden J, Paes AH, Bakker A. Angiotensin converting enzyme inhibitor associated cough: a population-based case-control study. J Clin Epidemiol. 1995;48 (6):851-857. doi:10.1016/0895-4356(94)00231-E

23. Caldeira D, David C, Sampaio C. Tolerability of angiotensin-receptor blockers in patients with intolerance to angiotensin-converting enzyme inhibitors: a systematic review and meta-analysis. $\mathrm{Am}$ J Cardiovasc Drugs. 2012;12(4):263-277. doi:10.1007/BF03261835

24. Giles TD, Oparil S, Silfani TN, Wang A, Walker JF. Comparison of increasing doses of olmesartan medoxomil, losartan potassium, and valsartan in patients with essential hypertension. J Clin Hypertens (Greenwich). 2007;9(3):187-195. doi:10.1111/j.1524-6175.2007. 06395. $\mathrm{x}$

25. Burke TA, Sturkenboom MC, Lu SE, Wentworth CE, Lin Y, Rhoads GG. Discontinuation of antihypertensive drugs among newly diagnosed hypertensive patients in UK general practice. $J$ Hypertens. 2006;24(6):1193-1200. doi:10.1097/01.hjh.000022 6211.95936.f5

26. Williams B, Mancia G, Spiering W, et al. 2018 ESC/ESH guidelines for the management of arterial hypertension. Eur Heart J. 2018;39 (33):3021-3104.

27. Gupta AK, Arshad S, Poulter NR. Compliance, safety, and effectiveness of fixed-dose combinations of antihypertensive agents: a meta-analysis. Hypertension. 2010;55(2):399-407. doi:10.1161/ HYPERTENSIONAHA.109.139816

28. Vrijens B, Vincze G, Kristanto P, Urquhart J, Burnier M. Adherence to prescribed antihypertensive drug treatments: longitudinal study of electronically compiled dosing histories. BMJ. 2008;336 (7653):1114-1117. doi:10.1136/bmj.39553.670231.25

29. Curb JD, Borhani NO, Blaszkowski TP, Zimbaldi N, Fotiu S, Williams W. Long-term surveillance for adverse effects of antihypertensive drugs. JAMA. 1985;253(22):3263-3268. doi:10.1001/ jama.1985.03350460063022

30. Nygaard B, Strandgaard S. Marked hepatotoxicity associated with losartan treatment. Blood Press. 1996;5(3):190-191. doi:10.3109/ 08037059609062128

31. Tabak F, Mert A, Ozaras R, et al. Losartan-induced hepatic injury. $J$ Clin Gastroenterol. 2002;34(5):585-586. doi:10.1097/00004836200205000-00022

32. Rene JM, Buenestado J, Sese E, Minana JM. [Acute hepatitis induced by valsartan]. Med Clin (Barc). 2001;117(16):637-638. doi:10.1016/ s0025-7753(01)72204-x

\section{Publish your work in this journal}

Drug Design, Development and Therapy is an international, peerreviewed open-access journal that spans the spectrum of drug design and development through to clinical applications. Clinical outcomes, patient safety, and programs for the development and effective, safe, and sustained use of medicines are a feature of the journal, which has also been accepted for indexing on PubMed Central. The manuscript management system is completely online and includes a very quick and fair peer-review system, which is all easy to use. Visit http://www. dovepress.com/testimonials.php to read real quotes from published authors. 